TI 2015-128/VII

Tinbergen Institute Discussion Paper

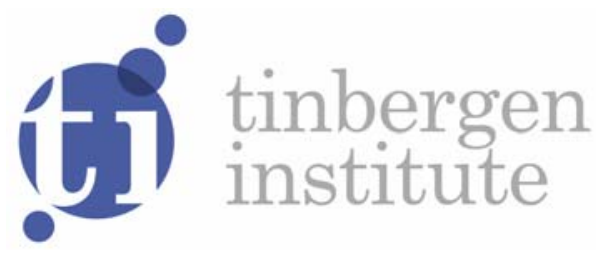

\title{
Voluntary Disclosure Programs for Tax Evaders
}

Heiner Schmittdiel

Erasmus School of Economics, Erasmus University Rotterdam, and Tinbergen Institute, the Netherlands. 
Tinbergen Institute is the graduate school and research institute in economics of Erasmus University Rotterdam, the University of Amsterdam and VU University Amsterdam.

More TI discussion papers can be downloaded at http://www.tinbergen.nl

Tinbergen Institute has two locations:

Tinbergen Institute Amsterdam

Gustav Mahlerplein 117

1082 MS Amsterdam

The Netherlands

Tel.: +31(0)20525 1600

Tinbergen Institute Rotterdam

Burg. Oudlaan 50

3062 PA Rotterdam

The Netherlands

Tel.: +31(0)10 4088900

Fax: +31(0)10 4089031 


\title{
Voluntary Disclosure Programs for Tax Evaders
}

\author{
Heiner Schmittdiel ${ }^{\mathrm{I}}$
}

November 17, 2015

\begin{abstract}
In this paper, we develop a model that can explain why governments may want to choose to offer a voluntary disclosure program that allows people who withheld taxes to turn themselves in without punishment. We find that such a leniency rule not only increases government revenue when it comes as a surprise, but even when taxpayers anticipate it.
\end{abstract}

Keywords: Tax compliance, voluntary disclosure, guilt JEL: $\mathrm{H}_{2} 6, \mathrm{~K}_{34}, \mathrm{~K}_{4} \mathrm{O}$

${ }^{\mathrm{I}}$ Department of Economics, Erasmus University Rotterdam, and Tinbergen Institute. E-mail: schmittdiel@ese.eur.nl 


\section{Introduction}

There are different ways a government can show mercy after a citizen has become clean about tax evasion: An amnesty is often granted for a limited time only, it may be confined to a certain group of perpetrators and may come with a fine, albeit lower than normal. It does, however, promise exemption from further criminal prosecution when withheld taxes are declared and paid. Sometimes, tax authorities also give tax offenders a break by allowing a remission of due taxes due to personal hardships. Over and above such temporary policies, many governments show permanent leniency towards perpetrators that turn themselves in (see Langenmayr 2015 for an overview). The question arises whether such voluntary disclosure programs sustainably increase government revenue or whether they destroy the deterrence effect of the penal code.

Tax evasion has recently been a popular topic in international news. Particularly in Germany, where punishment can be up to ten years imprisonment for severe infractions, some prominent cases have emerged in the recent past (see e.g. Koschnitzke 20I4). However, to many people's surprise, the German government has had a standing offer for tax offenders who turn themselves in. As a matter of fact, tax evasion is the only felony for which perpetrators can avoid criminal prosecution when they undo the crime (Fischer 20I4). Below a certain threshold, a tax evader can dodge punishment altogether as long as he comes clean about all his misreportings; he only needs to pay his tax debt plus interest. Above the threshold, punishment is also quite lenient, with only a small fine added to his tax debt. ${ }^{\mathrm{I}}$

In a rational world with perfect information, there would be no room for these

IThe rules have recently been tightened (Bundesministerium der Finanzen 20I4). From 2015 on, a fine of ten percent will be collected from 25,000 Euros of taxes withheld. It goes up to twenty percent for sums above I, O००,000 Euros. 
leniency programs. However, several things may cause a perpetrator to change his mind after withholding taxes: maybe his ethical convictions change, maybe he only realizes his true feeling of guilt once the deed has been done, maybe there is a shock on (his perception of) the probability to get caught. It may then be in the government's best interest to make it not too costly for tax evaders to turn themselves in. However, awareness of such a leniency policy may also cause more people to withhold taxes in the first place.

Building on Becker (I968) and Allingham and Sandmo (I972), we develop a model in which agents withhold taxes whenever the expected benefits of doing so exceed the expected punishment. As a variation on such classical models, however, we introduce another component to said punishment: in addition to potentially facing prosecution by the government, agents may also expose a feeling of guilt. We now assume that some agents may feel more or less guilty about cheating on their tax reports after handing them in. Our analysis provides insights into the costs and benefits for the government of offering agents the possibility to make a voluntary disclosure. We show that leniency does not only increase government revenue when it comes as a surprise, but even when it is anticipated by the agents.

We thereby offer a new explanation as to why we can observe permanent voluntary disclosure programs. Malik and Schwab (I99I) present a model in which agents are uncertain about their utility function. When they are risk-neutral, it is never optimal for the government to offer a guaranteed amnesty. Andreoni (I99I), on the other hand, shows that a (partial) 'permanent amnesty' can increase efficiency in a model where agents use the amnesty as insurance against an otherwise uninsurable consumption shock. In a more recent contribution, Bayer et al. (2015) explain the occurrence of amnesties by agents who discount possible future fines too much. In a strategic game between taxpayers and government, an equilibrium with almost- 
certain amnesties could arise.

The study that comes closest to our approach is that of Langenmayr (2015). Just like her, we consider a set of agents heterogeneous in their feeling of guilt with regards to evading taxes. This results in three different classes of agents: those who are always honest, those who initially cheat and then turn themselves in, and those who feel so little guilt that they are dishonest throughout. However, the assumption that drives the profitability of the voluntary disclosure program in her model is that there is a shock to agents' perception of the probability to get caught. While we do believe that in many cases this is the reason why people make use of voluntary disclosure, a permanent leniency program would also require permanent volatility of the (perceived) detection probability. Furthermore, in Langenmayr's (2015) paper, the fine for users of the leniency program is endogenous, with the detection probability being fixed. While there are arguments to defend either modeling approach, we believe that our choice to endogenize the auditing probability better reflects reality. Our model adds another justification why governments may want to provide a standing leniency offer to risk-neutral agents, even in times when there is little variation in tax offender conviction rates.

The remainder of the paper is structured as follows. The next section describes our model. Results are presented and discussed in Section 3 , followed by a concluding section. 


\section{The Model}

We set up a model in which agents base their decision to withhold taxes on their feeling of guilt, on the fine when caught, and on whether or not there is a voluntary disclosure program in place. The tax authorities, on the other hand, are treated as a simple profit center of the government that only cares about maximizing revenue subject to enforcement costs (cf. Heesen 2003). The sequence of events is as follows:

I. Nature draws guilt-types; the legislative sets the legal framework, including a fine for withholding taxes; agents receive taxable income.

2. Agents decide whether to withhold taxes, based on their guilt parameter and their expectation of the probability to get audited. ${ }^{2}$

3. The tax authorities decide on how many audits will take place by fixing the staff assignment. ${ }^{3}$

4. After handing in their tax reports, a random set of agents draws a new guilt parameter; the tax authorities may offer a voluntary disclosure program; tax withholders decide whether to make use of it.

5. Audits take place; convicted perpetrators are fined; government revenue is collected.

Before handing in their tax reports, agents face the following utility function:

$$
U_{i}=w-T+d_{i}-p f d_{i}-(1-p) 0-\theta_{i 1} d_{i}
$$

where $w$ is the gross wage, $T$ are taxes owed, $d_{i}$ is the amount of taxes that agents can withhold, $p$ is the probability to get audited and caught, $f>1$ is the penalty

${ }^{2}$ We will consider the case when agents anticipate a voluntary disclosure program and when they do not.

${ }^{3}$ Idem. In our model, there is informational symmetry concerning voluntary disclosure programs. 
factor when caught, and $\theta_{i 1} \mathcal{U}[0,1]$ determines the exogenous cost of withholding taxes, such as a feeling of guilt. Note that this means that we focus on the most interesting part of the population, namely those agents who may or may not choose to cheat, depending on the size of $p f$. Naturally, there is a (possibly quite large) set of taxpayers who would never consider cheating, thus having $\theta_{i 1}>1$. Hypothetically, one could also think of some agents with $\theta_{i 1}<0$, so a part of a population that feels joy, rather than guilt, when evading taxes. We disregard this possibility in our study. For simplicity, we assume that agents can choose to declare their taxes truthfully, i.e. $d_{i}=0$, or withhold a fixed amount $d_{i}=\bar{d}_{\cdot}^{4}$ There is a unit mass of agents, heterogeneous only in their uniformly distributed guilt factor $\theta_{i 1}$.

The tax authorities want to maximize revenue subject to enforcement costs. Net revenue is given by

$$
R=H T+D(T-\bar{d}+p f \bar{d})-\phi p
$$

where $H$ stands for the mass of agents who are honest, $D$ for the dishonest, and $\phi$ represents the auditing technology and hence the cost of increasing $p .5$ We assume the penalty factor $f$ is given by the institutional framework, so the tax authorities can only choose $p$. An interpretation for this could be that when we speak of the tax authorities, we mean an organ of the Executive branch that, while working on a fixed budget, can make some adjustments to $p$ over time, possibly due to a shift of priorities, whereas changes to $f$ can only be made in the long-run by the Legislative, or cannot be made at all because of constitutional constraints. Another explanation

${ }^{4}$ Of course, in this stylized model, the tax authorities could easily identify tax fraud: whoever declares $T-d_{1}$ rather than $T$ must be withholding taxes. This problem would be mitigated with sufficient heterogeneity in the tax burden, but implementing this would not yield additional insights in the scope of this analysis.

${ }^{5}$ Another facet of $\phi$ could be that too many audits (of innocent citizens) face public disapproval, see e.g. Leonard and Zeckhauser (1987). 
would be that a sizeable part of the 'punishment' of getting caught cannot be set by the government in the first place: it could be argued that the reaction of society to convicted tax offenders far outweighs any punishment manifested in the penal code, an idea that was already implemented in the seminal work of Allingham and Sandmo (1972).

After handing in their tax reports, some agents draw a new guilt factor $\theta_{i 2} \mathcal{U}[0,1]$, which will not only affect their decision on whether or not to withhold taxes in the future, but will also determine how they feel about the fact that there is a tax obligation that they concealed from the authorities. As a consequence an agent may have preferred to withhold more or less taxes than he initially decided. We assume that, after handing in his tax return, an agent can only increase the amount he declares, that is declare $T$ rather than $T-\bar{d}$, which may alleviate his feeling of guilt. If he does so and there is no leniency program in place, the agent would be treated as if he had been audited and caught, leading to a certain penalty of $f \bar{d}$. Clearly, an agent would never declare higher taxes, even when he feels more guilt than he initially thought, because $f>1$ implies his change in utility from turning himself in, $\Delta U_{i}=-f \bar{d}+\theta_{i 2} \bar{d}$, would be negative. ${ }^{6}$

However, the government may want to make use of the fact that some agents feel more guilty than they did when they handed in their tax return. Offering a voluntary disclosure program with little or no punishment could increase government revenue. We assume that agents anticipate they may draw a new $\theta$, but are not sure whether they will and, if so, whether it will be higher or lower. An agent knows that his guilt parameter will remain the same, i.e. $\theta_{i 2}=\theta_{i 1}$, with probability $q$. With probability $1-q$, he will receive a new draw $\theta_{i 2} \mathcal{U}[0,1] ; \theta_{i 2} \perp \theta_{i 1}$. It is crucial whether the

\footnotetext{
${ }^{6}$ This assertion follows from our assumption that the new guilt factor is drawn from the same distribution as the old one. If we allowed $\theta_{i 2} \geq 1$ we may very well observe agents turning themselves in, despite the absence of a leniency program.
} 
tax authorities realize they may want to offer a leniency program in the future and whether agents anticipate that. Our conjecture is that, when an agent is aware of the voluntary disclosure program ex ante, a particularly guilt-driven agent may still withhold taxes in the 'hope' of feeling less guilty in the future. If his hope does not materialize, he can always turn himself in later. Agents with low morals, however, may or may not withhold taxes. If they expect to draw a high $\theta$ in the next period, they could report truthfully, but it seems that cheating on the initial tax report is a superior strategy, because one cannot cheat retroactively. 


\section{Analysis}

In order to develop some intuition for our model, we first consider a case in which agents receive only one draw of their guilt parameter. Since there is no variation that could affect the agents' choice to withhold taxes, there is no use for the tax authorities to consider offering a voluntary disclosure program. We then allow some agents to receive a new draw of their guilt parameter and consider the implications of having a voluntary disclosure program when it is anticipated, and when it is not.

\section{I Benchmark with Static Guilt}

It is straightforward to see that an agent will withhold taxes whenever

$$
p f+\theta_{i 1}<1
$$

that is the expected punishment factor $p f$ and the agents' feeling of guilt $\theta_{i 1}$ are perfect substitutes. Note that if $p f>1$, nobody would cheat on taxes. ${ }^{7}$ It may at first seem counter-intuitive that a government would choose an expected punishment that does not exceed the potential benefits from misbehavior, but it can be argued that this reflects reality, at least for some parts of the penal code concerning taxes. There are several reasons why this may be the case. Slemrod (1992) claims that "it is extraordinarily expensive to arrange an enforcement regime so that, from a strict cost-benefit calculus, noncompliance does not appear attractive to many citizens" (p. 7). There can also be a natural or ethical upper bound to both punishment and prosecution itself; Stigler (1970) has argued that marginal deterrence requires marginal punishment, making it impractical to deter people from certain behavior. Needless to say, we do observe tax withholding, so apparently the expected punishment does not always exceed the benefits.

\footnotetext{
${ }^{7}$ This of course relies on our assumption that there are no notorious cheaters with $\theta_{i 1}<0$.
} 
In the absence of a voluntary disclosure program, the tax authorities can hence expect all agents below

$$
\hat{\theta}_{1}=1-p f
$$

to withhold taxes, with all others declaring truthfully. This leaves them with a mass of $1-p f$ of withholders, and a mass of $1-(1-p f)=p f$ of truthful reporters, so net revenue becomes

$$
R=(1-(1-p f)) T+(1-p f)(T-\bar{d}+p f \bar{d})-\phi p .
$$

It can already be seen that the cost of increasing $p$ is accompanied by two different benefits: a higher probability to get caught leads to less agents avoiding taxes, but government revenue also increases on the intensive margin: agents that withhold taxes are more often caught yielding additional revenue in the form of fines. Assuming the tax authorities can choose $p$ directly, net revenue maximization yields the following first order condition:

$$
\max _{p} R \Rightarrow 0=f \bar{d}-p f^{2} \bar{d}+f \bar{d}(1-p f)-\phi .
$$

From left to right, the terms in this condition show that an increase in the audit probability results in: a higher tax yield from less agents withholding, a decrease in fines collected when less agents withhold, higher revenue from an increase in convictions of those who do withhold, and higher auditing costs. Rearranging yields the optimal auditing probability:

$$
p^{*}=\frac{2 f \bar{d}-\phi}{2 f^{2} \bar{d}} .
$$

So the tax authorities will choose a positive auditing probability whenever $2 f \bar{d}>\phi$, see the discussion below. Furthermore, $p^{*}<1$ is always satisfied for $f>1$, so whenever a fine is charged on top of taxes withheld. Let us see how the optimal audit probability $p^{*}$ depends on the parameters of the model:

$$
\frac{\partial p^{*}}{\partial \phi}<0
$$


so, the cheaper it becomes to audit, the more often the tax authorities will do it;

$$
\frac{\partial p^{*}}{\partial \bar{d}}=\frac{1}{2 f^{2} \bar{d}^{2}}>0
$$

so the higher the amount that perpetrators can withhold, the more effort the tax authorities are going to put into detecting them;

$$
\frac{\partial p^{*}}{\partial f}=\frac{1}{f^{2}}-\frac{4(2 f \bar{d}-\phi)}{4 f^{3} \bar{d}}
$$

so it is not clear whether or not the tax authorities decrease the audit probability after increases in the exogenous fine factor. As a matter of fact, the negative effect of an increase in $f$ starts to overrule its positive effect on $p^{*}$ as soon as the total fine $\mathrm{ex}^{-}$ ceeds the total cost of increasing $p$, that is $\frac{\partial p^{*}}{\partial f}<0$ iff $\phi<f \bar{d}$. In other words, when a low total fine is increased, it leads to an increase in the audit probability, whereas for sufficiently large values of $f$, a further increase starts to lead to decreases in $p^{*}$. Consider the two mechanisms at work: first, increases in $f$ can make it worthwhile to increase $p$, because an increase in the audit probability may yield more net revenue, as can be seen in the numerator of Expression (3). To be more precise, the revenue for each $p$ (also) increases in $f$ because it implies less people withholding taxes and at the same time a higher punishment when caught. Second, increases in $f$ may allow the tax authorities to generate the same net revenue while setting a lower $p$. The downward effect of $f$ can be seen in the denominator of Expression (3). It exists because the revenue for each $p$ also decreases in $f$, for when less people withhold taxes also less people will be fined; over and above this, the higher the fine $f$ is, the bigger will be the loss from every person not fined, an effect that enters the equation multiplicatively. Now, when $f$ is already at a high level, a further increase of $p$ will actually decrease net revenue, because too few people will withhold taxes, thus be caught and forced to pay this relatively high fine.

Using our result for $p^{*}$, we can see that the agent who is indifferent between 
withholding taxes and reporting truthfully is characterized by:

$$
\hat{\theta}_{1}=\frac{\phi}{2 f \bar{d}}
$$

Note that this implies an interior solution as long as $0<\phi<2 f \bar{d}$. As we saw above, it must be reasonably "cheap" for the government to audit in order to pick a positive audit probability. When it becomes very cheap to audit, i.e. $\phi \rightarrow 0$, nobody will withhold taxes. This is so because costless auditing leads the tax authorities to set $p^{*}=\frac{1}{f}$, which is sufficient to deter even the least guilt-driven of agents from cheating. ${ }^{8}$

For later comparison, the generated net revenue when implementing the optimal strategy, i.e. using Expression (3) in Equation (2) is equal to:

$$
R\left(p^{*}\right)=T-\frac{\phi}{f}+\frac{\phi^{2}}{4 f^{2} \bar{d}}
$$

\subsection{Voluntary Disclosure after a New Draw of $\theta$}

When there is a chance that agents receive a new draw of $\theta$, the government can make use of the fact that some agents feel more guilty and would have preferred to declare higher taxes by offering a voluntary disclosure program after the deadline for tax reports, but before the audits take place. If there is no penalty on declarations under voluntary disclosure, exactly those agents will retroactively declare their taxes truthfully who would have done so from the beginning, had their guilt parameter always been the one they newly drew. That is, the agents for whom the following holds will turn themselves in: $\theta_{i 1}<\hat{\theta}_{1} \wedge \theta_{i 2}>\hat{\theta}_{1}$. In the remainder of this subsection, we will derive results for different information structures in order to find out when offering a voluntary disclosure program increases government revenue.

\footnotetext{
${ }^{8}$ Note that auditing everyone is not needed, even when it is free; this is so because agents base their decision to withhold taxes on the expected punishment.
} 


\subsection{New Draw of $\theta$ without Voluntary Disclosure}

We first analyze the implications of a new draw of the guilt parameter in the absence of a leniency program. We do, assume that agents foresee that their guilt factor may change in the future. Their utility function thus becomes:

$$
\begin{aligned}
U_{i} & =w-T+d_{i}-p f d_{i}-(1-p) 0-\mathbb{E} \theta d_{i} \\
& =w-T+d_{i}-p f d_{i}-(1-p) 0-\left(q \theta_{i 1}+(1-q) \mathbb{E} \theta_{i 2}\right) d_{i} \\
& =w-T+d_{i}-p f d_{i}-(1-p) 0-\left(q \theta_{i 1}+(1-q) \frac{1}{2}\right) d_{i} .
\end{aligned}
$$

Remember that agents cannot reverse their decision later, so they withhold taxes if $p f+q \theta_{i 1}+(1-q) \frac{1}{2}<1$, leading to a cutoff value of

$$
\tilde{\theta}_{1}=\frac{1}{2}+\frac{\frac{1}{2}-p f}{q}
$$

It is instructive to see what this condition implies for two extreme cases: First, nobody will withhold any taxes if $0>\frac{1}{2}+\frac{\frac{1}{2}-p f}{q}$ holds. This is equivalent to $p f>\frac{1}{2}+$ $\frac{1}{2} q$, so an expected punishment factor between $\frac{1}{2}$ and 1 is sufficient to deter everyone from cheating, depending on $q$. Second, everyone will cheat if $1<\frac{1}{2}+\frac{\frac{1}{2}-p f}{q}$, or $p f<\frac{1}{2}-\frac{1}{2} q$, so, again depending on $q$, an expected punishment factor between 0 and $\frac{1}{2}$ will induce everyone to withhold taxes. For given levels of $p$, the threshold guilt parameter reacts to changes in $q$ as follows:

$$
\frac{\partial \tilde{\theta}_{1}}{\partial q}=\frac{-\left(\frac{1}{2}-p f\right)}{q^{2}}
$$

So the marginal tax withholder's guilt parameter increases in $q$ for large values of $p f$ and decreases for low levels. This means that for a large expected fine factor, more agents keeping their guilt parameter leads to more tax withholding. The reason for this is that an increase in $q$ puts less weight on the expected guilt parameter of $\frac{1}{2}$, which favors honesty for high $p f$, and cheating for low values. Keep in mind, though, that this analysis disregards any impact that $q$ may have on $p$. In the absence 
of a leniency program, the tax authorities fix the audit probability optimizing the following expression:

$$
\begin{aligned}
R & =\left(1-\tilde{\theta}_{1}\right) T+\tilde{\theta}_{1}(T-\bar{d}+p f \bar{d})-\phi p \\
& =\left(\frac{1}{2}-\frac{\frac{1}{2}-p f}{q}\right) T+\left(\frac{1}{2}+\frac{\frac{1}{2}-p f}{q}\right)(T-\bar{d}+p f \bar{d})-\phi p,
\end{aligned}
$$

which would yield the following audit probability:

$$
\tilde{p}=\frac{(q+3) f \bar{d}-2 q \phi}{4 f^{2} \bar{d}}=\frac{q+3}{4 f}-\frac{q \phi}{2 f^{2} \bar{d}} .
$$

Note that naturally, with $q=1$, this is consistent with what we found above for $p^{*}{ }^{9}$ For $q \rightarrow 0$ the distribution of expected guilt-types becomes more and more narrow, until all agents know they will draw a new $\theta$ and make their decisions based on $\mathbb{E} \theta=\frac{1}{2}$. When $q=0$, Equation (5) and thus also Equation (6) and Equation (7) are not defined. The tax authorities can then simply deter everyone from withholding taxes by setting $p=\frac{1}{2 f}$, which is profitable when $\bar{d} \geq \frac{\phi}{2 f}$. Generally, in the absence of voluntary disclosure, the audit probability reacts to changes in $q$ as follows:

$$
\frac{\partial \tilde{p}}{\partial q}=\frac{f \bar{d}-2 \phi}{4 f^{2} \bar{d}} .
$$

So, when the benefit from auditing, or more precisely the total fine $f \bar{d}$ collected from one convicted perpetrator, is high compared to the cost of auditing $\phi$, a higher probability of agents keeping their type comes about with a higher audit probability. As we can see in Equation (5), increases in $q$ lead to more tax withholding for large $p f$, and to less withholding for small values of $p f$, c.p. This is so because a large $p f$ implies that only agents with a very low $\theta_{i 1}$ consider withholding taxes; if now $q$ increases, these agents are less 'afraid' that they will make a new draw $\theta_{i 2}$, which in expected terms they value at $\frac{1}{2}$, a figure that would deter them from withholding

${ }^{9}$ Also note that, just like in the benchmark case, the audit probability always remains below 1 as long as $f>1$. Naturally, it will be positive when the numerator is positive. 
taxes. Likewise, for low $p f$, an increase in $q$ means agents with a high $\theta_{i 1}$ can more confidently make an honest tax report, because the chance of receiving a low draw of $\theta_{i 2}$ that would encourage cheating decreases. Similarly, when the fine to be collected is rather high, increases in $q$ warrant a lower $p$, in part due to the fact that there are already not so many perpetrators, and there is no need to further deter the increasingly heterogeneous population of expected types. When the fine is low, however, the increase in heterogeneity means there is a larger set of agents to be susceptible to deterrence, so $p$ increases.

With this understanding of the impact of $q$ on $\tilde{p}$, let us reconsider our analysis of the effect of $q$ on $\tilde{\theta}_{1}$ :

$$
\frac{\mathrm{d} \tilde{\theta}_{1}}{\mathrm{~d} q}=\frac{\partial \tilde{\theta}_{1}}{\partial q}+\frac{\partial \tilde{\theta}_{1}}{\partial \tilde{p}} \frac{\mathrm{d} \tilde{p}}{\mathrm{~d} q}=\frac{-\left(\frac{1}{2}-\tilde{p} f\right)}{q^{2}}-\frac{f}{q}\left(\frac{f \bar{d}-2 \phi}{4 f^{2} \bar{d}}\right) .
$$

Using our result from Equation (7) this yields after some rewriting:

$$
\frac{\mathrm{d} \tilde{\theta}_{1}}{\mathrm{~d} q}=\frac{1}{4 q^{2}}>0
$$

So when the tax authorities pick the optimal auditing probability, more agents keeping their initial guilt factor leads to an increase of the marginal tax withholder's parameter, and thus to more tax withholding. In other words, the tax authorities design the auditing probability such that more uncertainty concerning agents' guilt parameters leads to more tax honesty.

Substituting Expression (7) into Equation (6), net revenue becomes, after some rewriting:

$$
R(\tilde{p})=T+\frac{-1+2 q-q^{2}}{16} \bar{d}+\frac{-3-2 q+q^{2}}{4} \frac{\phi}{f}+\frac{2 q-q^{2}}{4} \frac{\phi^{2}}{f^{2} \bar{d}} .
$$

Once again, this is a general form for which our benchmark in the previous subsection was a special case; substituting $q=1$ into Equation (8) will yield exactly the result found in Equation (4). 


\subsubsection{Voluntary Disclosure is Not Anticipated}

The tax authorities now offer a non-anticipated leniency program with no punishment for agents who turn themselves in. Everyone who has $\theta_{i 2}>\hat{\theta}_{2}=1-\tilde{p} f$ will either turn themselves in or never have withheld taxes in the first place. It is impor tant to realize that offering a voluntary disclosure program comes at no immediate cost to the tax authorities when agents do not anticipate it will be offered. There is only the benefit of some agents making use of the program by retroactively declaring higher taxes. How many agents make use of voluntary disclosure depends on the absolute and relative size of $\tilde{\theta}_{1}=\frac{1}{2}+\frac{\frac{1}{2}-\tilde{p} f}{q}$ and $\hat{\theta}_{2}=1-\tilde{p} f$. To be more precise, when $\tilde{\theta}_{1}>\hat{\theta}_{2}$ there is a mass of

- $1-\tilde{\theta}_{1}$ agents who were honest from the beginning, ${ }^{\text {,o }}$

- $q\left(\tilde{\theta}_{1}-\hat{\theta}_{2}\right)$ agents who withheld taxes, but turned themselves in after realizing their guilt parameter did not change,

- $(1-q)\left(\tilde{\theta}_{1}\left(1-\hat{\theta}_{2}\right)\right)$ agents who turned themselves in after learning their new parameter,

- $q \hat{\theta}_{2}$ agents whose guilt parameter was low enough to cheat from the outset,

- $(1-q)\left(\tilde{\theta}_{1} \hat{\theta}_{2}\right)$ agents who, after receiving a new draw still find it worthwhile to withhold taxes.

If, on the other hand $\tilde{\theta}_{1}<\hat{\theta}_{2}$, a mass of

- $1-\tilde{\theta}_{1}$ agents make an honest report from the outset, ${ }^{\mathrm{II}}$

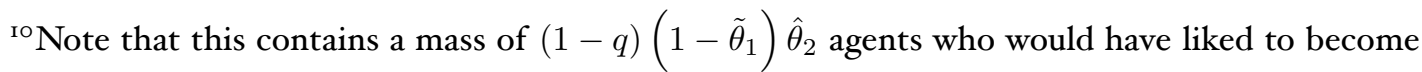
cheaters, but cannot undo their honest tax report.

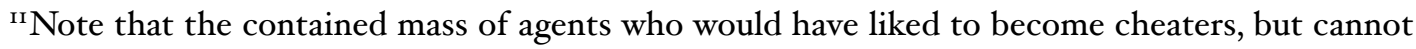
undo their honest tax report $(1-q)\left(1-\tilde{\theta}_{1}\right) \hat{\theta}_{2}+q\left(\hat{\theta}_{2}-\tilde{\theta}_{1}\right)$ is broader than in the case when $\tilde{\theta}_{1}>\hat{\theta}_{2}$.
} 
- $(1-q) \tilde{\theta}_{1}\left(1-\hat{\theta}_{2}\right)$ agents turn themselves in after withholding taxes, because they drew a higher guilt parameter,

- $q \tilde{\theta}_{1}$ agents cheat from the outset while keeping their parameter,

- $(1-q) \tilde{\theta}_{1} \hat{\theta}_{2}$ agents will not turn themselves in after withholding taxes, in spite of receiving a new guilt parameter.

So offering a surprise voluntary disclosure program will simply increase the government revenue, as compared to the expression in Equation (8), by exactly

$$
\Delta_{L R 1} R=(\bar{d}-\tilde{p} f \bar{d})\left[q\left(\tilde{\theta}_{1}-\hat{\theta}_{2}\right)+(1-q)\left(\tilde{\theta}_{1}\left(1-\hat{\theta}_{2}\right)\right)\right]
$$

in the case of $\tilde{\theta}_{1}>\hat{\theta}_{2}$, and by

$$
\Delta_{L R 2} R=(\bar{d}-\tilde{p} f \bar{d}) *(1-q) \tilde{\theta}_{1}\left(1-\hat{\theta}_{2}\right)
$$

if $\tilde{\theta}_{1}<\hat{\theta}_{2}$. The only requirement for these expressions to be positive is that $p f<1$, which has been discussed above. Nonetheless, one can see that the profitability of a surprise leniency program not only depends on $q$, but also on the relative size of $\tilde{\theta}_{1}$ and $\hat{\theta}_{2}$, and thereby also on $\tilde{p} f$. More precisely, we end up in the first case if $\tilde{\theta}_{1}>\hat{\theta}_{2}$, which is equivalent to $\tilde{p} f<\frac{1}{2}$ or $1<q\left(\frac{2 \phi}{f d}-1\right)$. In order for this to be possible, we must have $2 \phi>f \bar{d}$. The crucial difference between these cases is that in the first scenario, there is a group of agents making use of voluntary disclosure that is missing in the second scenario: those agents that withheld taxes in the hope of receiving a lower draw of the guilt parameter, but eventually turn themselves in when they realize their parameter did not change. Analogously, there is group of agents in the second scenario that is missing in the first: those who regret their decision to make an honest tax report, even though their parameter did not change. For the intuition behind these decisions we refer to the discussion about the impact of $q$ on $\tilde{p}$ in the previous subsection. 
It could be argued that the tax authorities may want to revise the audit probability once voluntary disclosure has been offered and taken advantage of - either to catch the remaining perpetrators or to save resources from unnecessary audits. It is quite conceivable that the tax authorities consider offering voluntary disclosure before setting the audit probability, but we do not focus on such a situation here. While it may be possible to surprise agents with a leniency program, sudden changes in the auditing frequency may not be easy to implement and will hardly come unnoticed; the tax authorities would face yet another credibility problem. A brief sketch of the resulting corner solution is provided in the Appendix.

To summarize, if the tax authorities only consider offering a voluntary disclosure program after fixing the audit probability, their revenue will simply increase due to the agents who turn themselves in. Let us now look at what happens when agents anticipate that a leniency program will be offered.

\subsubsection{Anticipated Voluntary Disclosure}

An agent who anticipates a program will be offered by the tax authorities faces the following decision: When he decides to declare truthfully, he can expect:

$$
U_{i}=w-T+(q) 0+(1-q) 0,
$$

when he decides to withhold taxes in the first period, however, he derives an expected utility of

$\mathbb{E} U_{i}=w-T+\bar{d}+(q) \max \left\{-\bar{d},-p f \bar{d}-\theta_{i 1} \bar{d}\right\}+(1-q) \mathbb{E} \max \left\{-\bar{d},-p f \bar{d}-\theta_{i 2} \bar{d}\right\}$.

Clearly, the second strategy (weakly) dominates the first one, because it will always at least yield $w-T$. Note that this is regardless of any auditing probability the government may choose. As a consequence, all agents will decide to withhold taxes in the first period. The tax authorities will then face two groups of agents that turn 
themselves in after a voluntary disclosure program has been offered: agents who had a high $\theta_{i 1}$ and did not receive a new draw, and those who received a high new draw. More precisely, the following mass of agents will make use of the program:

$$
H_{2}=(q)\left(1-\hat{\theta}_{1}\right)+(1-q)\left(1-\hat{\theta}_{2}\right)
$$

where $\hat{\theta}_{1}=\hat{\theta}_{2}=1-p f$, which gives

$$
H_{2}=p f
$$

As a consequence, revenue is given by

$$
R=T-\bar{d}+(p f) \bar{d}+(1-p f) p f \bar{d}-\phi p
$$

yielding

$$
p^{*}=\frac{2 f \bar{d}-\phi}{2 f^{2} \bar{d}}
$$

as in the Benchmark case when agents keep their guilt parameter for sure, and thus also the same revenue, as described in Equation (4).

To summarize, when agents anticipate that a voluntary disclosure program is offered, the government will make exactly the same revenue as if there had not been (the possibility of) a new draw of agents' guilt parameter.

\subsubsection{Comparison}

When there is the possibility to offer an unanticipated voluntary disclosure program, it clearly raises revenue compared to a situation without a leniency program. The open question is now whether even anticipated voluntary disclosure increases government revenue. Let us recall Equation (4), which not only describes net revenue when agents keep their guilt parameter with certainty, but also for the case when they do and voluntary disclosure is anticipated:

$$
R\left(p^{*}\right)=T-\frac{\phi}{f}+\frac{\phi^{2}}{4 f^{2} \bar{d}} .
$$


To compare, the revenue when there is no leniency program from Equation (8) can be rewritten to:

$$
R(\tilde{p})=T-\frac{(1-q)^{2}}{16} \bar{d}+\left(\frac{(1-q)^{2}}{4}-1\right) \frac{\phi}{f}+q(2-q) \frac{\phi^{2}}{4 f^{2} \bar{d}} .
$$

We can now see that net revenue with an anticipated voluntary disclosure program is larger than with none whenever $R\left(p^{*}\right)>R(\tilde{p})$, or

$$
\frac{(1-q)^{2}}{16} \bar{d}>\left(-1+2 q-q^{2}\right) \frac{\phi^{2}}{4 f^{2} \bar{d}} \text {. }
$$

It is noteworthy that, except for $q=1$ of course, this is always satisfied, because $\left(-1+2 q-q^{2}\right)<0 \forall 0 \leq q<1$. In other words, as soon as there is a small chance that agents draw a new guilt parameter, the government revenue even with an anticipated voluntary disclosure program is always larger than that with no leniency program at all. The reason for this is that offering an anticipated program allows the agents to adjust their decisions on withholding taxes to their relevant guilt parameters once they are known. This yields more revenue than a situation where agents have to base their decisions on their expecations of guilt parameters. We have already seen that revenue with a surprise voluntary disclosure program is larger than with no leniency rule. We can thus conclude that, whenever there is a chance that agents' attitude towards tax honesty may vary over time, the tax authorities would always like to offer a voluntary disclosure program. 


\section{Concluding Remarks}

This paper presents a model that adds to the existing explanations as to why governments may offer voluntary disclosure programs for tax evaders. When parts of the populations feel more or less guilty about evading taxes after reports are due, government revenue can be increased by offering tax evaders a chance to turn themselves in, even when this is costless for them.

We have shown that the tax authorities' reaction to changes in the exogenously set punishment for tax evasion can go in two directions. When said fine is relatively low, increasing it will lead them to expanding their auditing efforts, with the opposite being true for high fines. We further show that the immediate effect of the volatility of people's feeling of guilt on tax evasion is ambiguous: a higher amount of agents receiving a new draw may lead to more or less tax withholding, depending on how severely it is punished. In equilibrium, however, the tax authorities will set the frequency of audits such that more people making a new draw leads to less tax evasion.

The key result of our study is that government revenue not only rises with surprise voluntary disclosure, but even when such a program is anticipated. This holds true in spite of the concern that an anticipated program initially leads to more tax evasion, which is often stated in the literature and confirmed by our analysis. In a dynamic setting, however, things may change. If the gains from a surprise voluntary disclosure program are much larger than those of an anticipated one, the government may find it in their best interest to refrain from using voluntary disclosure at times (cf. Andreoni I991, Bayer et al. 2015). The rationale behind this is that it may be worthwhile to forego the benefits of anticipated voluntary disclosure in some periods in order to alter agents' expectations and hence reap the possibly larger benefits of a surprise program in some other periods. 
Discussing the welfare implications of voluntary disclosure is not an easy task. Slemrod (2007) makes the point that "[a]lthough the cost of [more auditing] is a true resource cost, the revenue brought in does not represent a net gain to the economy, but rather a transfer from private (noncompliant) citizens to the government" (p. 43). A leniency program expands the choice set of taxpayers, giving them another tool to maximize utility. At the same time, government revenue increases without incurring said additional resource costs, let alone the social cost of inevitably auditing a number of compliant citizens. On the other hand, the existence of voluntary disclosure programs may be perceived as unfair, because it grants criminals the opportunity to dodge punishment. The wish to avoid the long-term effects of this notion can be another explanation why leniency programs are not as ubiquitous as our analysis would prescribe. 


\section{References}

Allingham, M. G. and A. Sandmo (I972): "Income tax evasion: a theoretical analysis", Journal of Public Economics, I, 323-338.

Andreoni, J. (I99I): "The desirability of a permanent tax amnesty", Journal of Public Economics, 45, I43-I59.

Bayer, R.-C., H. Oberhofer, and H. Winner (2015): "The occurrence of tax amnesties: Theory and evidence", Journal of Public Economics, I25, 70-82.

Becker, G. (I968): “Crime and Punishment: An Economic Approach”, Journal of Political Economy, 76, I69-217.

Bundesministerium der Finanzen (20I4): "Regeln zur strafbefreienden Selbstanzeige werden verschärft”, URL http://www.bundesfinanzministerium.de/ Content/DE/Pressemitteilungen/Finanzpolitik/2OI4/o9/2OI4-o9-24-PM38.html, retrieved on $2015^{-08}-15$.

Fischer, T. (2OI4): “Täter, die sich für Opfer halten”, Zeit, URL http://www.zeit.de/ 20I4/07/steuersuender-steuerhinterziehung-selbstanzeige, retrieved on 2015-08-05.

Heesen, E. (2003): "Selbstanzeige als Instrument zur Kriminalitätsbekämpfung”, Wiesbaden: Deutscher Universitäts-Verlag.

Koschnitzke, L. (20I4): “I5I Fußballplätze für Uli Hoeneß”, Zeit, URL http:// www.zeit.de/wirtschaft/2OI4-O2/steuerhinterziehung-prominente-steuersuender, retrieved on $2015^{-10}-15$.

Langenmayr, D. (2015): "Voluntary Disclosure of Evaded Taxes - Increasing Revenues, or Increasing Incentives to Evade?", Journal of Public Economics (forthcoming). 
Leonard, H.B. and R.J. Zeckhauser (I987): "Amnesty, enforcement, and tax policy", Tax Policy and the Economy, I, 55-86.

Malik, S. M. and R. M. Schwab (I99I): “The economics of tax amnesties”, Journal of Public Economics, 46, 29-49.

Slemrod, J. (I992): "Why People Pay Taxes: Tax Compliance and Enforcement", Ann Arbor, MI: The University of Michigan Press.

Slemrod, J. (2007): "Cheating Ourselves: The Economics of Tax Evasion”, Journal of Economic Perspectives, 2I(I), 25-48.

Stigler, G. J. (I970): “The Optimum Enforcement of Laws”, Journal of Political Economy, 78, 526-536. 


\section{Appendix}

\section{Revised $p$ after a Surprise Voluntary Disclosure Program}

Assuming the tax authorities can revise their decision on the audit probability after offering an unanticipated voluntary disclosure program, they face the following revenue:

$$
R=H(\tilde{p}) * T+D(\tilde{p}) *\left(T-\bar{d}+p_{2} f \bar{d}\right)-\phi p_{2}
$$

where the mass of agents that are (ex post) honest is

$$
H=1-\tilde{\theta}_{1}+q\left(\tilde{\theta}_{1}-\hat{\theta}_{2}\right)+(1-q)\left(\tilde{\theta}_{1}\left(1-\hat{\theta}_{2}\right)\right)=1-q \hat{\theta}_{2}-(1-q) \tilde{\theta}_{1} \hat{\theta}_{2},
$$

and the mass of agents that are dishonest is

$$
D=q \hat{\theta}_{2}+(1-q) \tilde{\theta}_{1} \hat{\theta}_{2}
$$

with $\tilde{\theta}_{1}=\frac{1}{2}+\frac{\frac{1}{2}-\tilde{p} f}{q}$ and $\hat{\theta}_{2}=1-\tilde{p} f$. Since the mass of tax withholders does not depend on the revised audit probability $p_{2}$, the result will be a corner solution - as soon as $f \bar{d}>\phi$, the tax authorities want to audit everyone, and noone otherwise.

\section{Allowing for a Higher Guilt Parameter}

In the main text, we have focussed on those agents with $\theta \in[0,1]$. This entails that when there is no expected punishment for withholding taxes, $p f=0$, even the agent with the highest possible guilt parameter would only marginally decide not to cheat. Naturally, it can be argued that there is a sizable part of society that would make an honest tax report even in the absence of punishment, namely those agents with $\theta>1$. Allowing for such a broader distribution of types in our model does not have a qualitative impact on our results. What does change, is that there is a larger set of agents that is honest from the beginning. 
Consider the benchmark case of subsection 3.I: when we allow $\theta-\mathcal{U}[0, b] ; b>1$, the tax authorities' revenue changes to

$$
R=(b-(1-p f)) T+(1-p f)(T-\bar{d}+p f \bar{d})-\phi_{1} p
$$

That is, the marginal considerations of the tax authorities remain unaffected, because their decisions do not have an impact on the additional agents with $\theta \in[1, b]$. There is simply a larger fraction of agents that is honest in their tax reports.

It is interesting to note, though, that even when there is no leniency program in place, we may observe some agents who turn themselves in once that agents draw a new $\theta$. The reason for this is that it is possible that an agent who cheated on his tax report may find it in his best interest to come clean about it whenever his new draw of $\theta$ is very high. More specifically, it has to be so high that he does not mind the certain punishment when alleviating his guilt. The marginal cheater's guilt parameter from Equation 5 changes to:

$$
\tilde{\theta}_{1}=\frac{b}{2}+\frac{1-\frac{b}{2}-p f}{q}
$$

leading to a revenue function of

$$
R=\left(\frac{b}{2}-\frac{1-\frac{b}{2}-p f}{q}\right) T+\left(\frac{b}{2}+\frac{1-\frac{b}{2}-p f}{q}\right)(T-\bar{d}+p f \bar{d})-\phi_{1} p .
$$

So unlike above, the larger dispersion of guilt-types does affect the number of cheaters, not only the number of honest tax payers. This is so because agents now realize they may draw a much higher parameter later, making cheating less attractive, c.p. Consequently, the optimal auditing probability also changes to:

$$
\tilde{p}=\frac{4-b+b q}{4 f}-\frac{q \phi_{1}}{2 f^{2} \bar{d}} .
$$

Note that for all $b>1$ this is always less than the result we found when $\theta \in[0,1]$. It is only positive for $b<\frac{2 q \phi_{1}}{f \bar{d}(q-1)}-\frac{4}{q-1}$, which is only possible for $\frac{2 q \phi_{1}}{f \bar{d}}<4$. Despite 
the lower auditing probability, allowing for higher guilt parameters reduces overall cheating. This result extends to the other information structures discussed in the main text.

\section{Voluntary Disclosure is Anticipated and Carries a Small Fine}

In the main text, withholding taxes was a (weakly) dominant strategy for all agents when the voluntary disclosure was anticipated, because it implied everyone could revise their decision on tax withholding costlessly. We now introduce a small fine factor $\Delta f$ that is imposed whenever agents turn themselves in. The decision problem now looks as follows:

When an agent decides to declare truthfully, he can expect:

$$
U_{i}=w-T
$$

when he decides to withhold taxes in the first period, however, he derives an ex$^{-}$ pected utility of

$$
\begin{array}{r}
\mathbb{E} U_{i}=w-T+\bar{d}+(q) \max \left\{-\bar{d}-\Delta f \bar{d},-p f \bar{d}-\theta_{i 1} \bar{d}\right\} \\
+(1-q) \mathbb{E} \max \left\{-d-\bar{\Delta} f \bar{d},-p f \bar{d}-\theta_{i 2} \bar{d}\right\} .
\end{array}
$$

It is apparent that cheating no longer clearly dominates. The agents' choice depends on the parameters of the model and the magnitude of $p$. We need to distinguish up to four cases to determine the benefit of withholding taxes for each agent, depending on whether or not they would make use of the program when they keep their guilt parameter, and whether or not they would when making a new draw.

Let us solve by backward induction and consider the case when an agent has already decided to withhold taxes. Regardless of whether or not he made a new draw, he would make use of voluntary disclosure if the benefits outweigh the costs: $-\bar{d}-$ 
$\Delta f \bar{d}>-p f \bar{d}-\theta_{i} \bar{d}$. This means the marginal user of the voluntary disclosure program will have a guilt parameter of

$$
\hat{\theta}_{1}=1-(p f-\Delta f) .
$$

When agents make the decision to withhold taxes in the first place, they compare this cutoff value to their current guilt parameter and their expected parameter in case they face a new draw, which is $\mathbb{E} \theta_{2}=\frac{1}{2}$. Thus, when confronted with a new draw, agents expect to make use of the program only if $\frac{1}{2}<1-(p f-\Delta f)$.

We will now look at the four different cases. If an agent expects to use the leniency rule regardless of making a new draw, so if $\theta_{i 1}>\hat{\theta}_{1}$ and $\frac{1}{2}>\hat{\theta}_{1}$, he will withhold taxes if:

$$
\bar{d}>q(\bar{d}+\Delta f \bar{d})+(1-q)(\bar{d}+\Delta f \bar{d}) .
$$

Note that this is never satisfied. If he expects to use the leniency rule when making a new draw, but not when keeping his current draw, so if $\theta_{i 1}<\hat{\theta}_{1}$ and $\frac{1}{2}>\hat{\theta}_{1}$, he will withhold taxes if:

$$
\bar{d}>q\left(p f \bar{d}+\theta_{i 1}\right)+(1-q)(\bar{d}+\Delta f \bar{d}) .
$$

This yields a cutoff value of $\tilde{\theta}_{1}=1-p f-\frac{1-q}{q} \Delta f$. Note that this is always smaller than $\hat{\theta}_{1}$. When the agent expects to use the leniency rule when keeping his draw, but not when making a new one, so when $\theta_{i 1}>\hat{\theta}_{1}$ and $\frac{1}{2}<\hat{\theta}_{1}$, he will withhold taxes if:

$$
\bar{d}>q(\bar{d}+\Delta f \bar{d})+(1-q)\left(p f \bar{d}+\frac{1}{2} \bar{d}\right) .
$$

When an agent does not expect to use the voluntary disclosure program, regardless of whether or not he makes a new draw, he will withhold taxes if:

$$
\bar{d}>q\left(p f \bar{d}+\theta_{i 1}\right)+(1-q)\left(p f \bar{d}+\frac{1}{2} \bar{d}\right) .
$$


This yields a cutoff value of $\tilde{\theta}_{1}=\frac{1}{2}+\frac{\frac{1}{2}-p f}{q} \Delta f$. With this information, the tax authorities can maximize their revenue, choosing $p$. 